\title{
Lumbar Myelography in a Crab-Eating Raccoon (Procyon cancrivorus)
}

\author{
Bruno Watanabe Minto', Paloma do Espírito Santo Silva', Paulo Vinícius Tertuliano Marinho², Carolina \\ Camargo Zani ${ }^{3}$, Pedro Henrique Ferreira Teles ${ }^{4}$, Karin Werther ${ }^{4}$, Tiago Barbalho Lima' \& Júlio Carlos Canola ${ }^{4}$
}

\begin{abstract}
Background: The Crab-eating raccoon (Procyon cancrivorus) is a nocturnal mammal and lives in savannah, but loss of their natural habitat makes increase cases of traffic accidents on the roads. A growing number of wildlife are treated in veterinary hospitals, but we have some limitation about the correct interpretation of the diagnostic test, specially because, even the tests were not described. Myelography is a radiographic technique indicated for compressive lesions of the spinal cord that are not seen on plain radiographs. The present report aims to describe, for the first time, a lumbar myelogram performed in a paraplegic crab-eating raccoon after it suffer a traffic trauma.

Case: A free living adult, $8-\mathrm{kg}$, female raccoon was presenting acute paraplegia and swelling in the region of the left humerus was referred at veterinary hospital. The patient was alert and aggressive, good body score and no signs of active bleeding. The animal temper did not allow approaching it; therefore, physical and neurological examinations were not feasible. The raccoon was tranquilized $\left(1.6 \mathrm{~mL}\right.$ of nilperidol ${ }^{\circledR}$ intramuscular), anesthetized (propofol, dose-effect intravenous) and tracheal intubation to provide oxygen and the patient was monitored continuously, followed by referred for radiology service. The simple radiograph showed a complete transverse fracture in the humerus and compression fracture of the twelfth thoracic vertebra (T12), being then indicated the myelographic examination to assess the extent of spinal cord compression. The lumbar region was surgical antisepsis prepared. After being properly positioned in lateral decubitus with moderate cranial flexion of the trunk, the patient underwent lumbar puncture by inserting a spinal needle between the 5 th and 6th intervertebral lumbar spaces. The spinal needle was introduced slightly caudolaterally to the spinous process of the 6 th lumbar vertebra and cranioventrally directed at an angle of $45^{\circ}$. Then, the needle was pierced through the ligamentum flavum and the dura mater while, concomitantly, we observed the tail moving and the cerebrospinal fluid (CSF) output while the contrast was injected. The contrast iohexol $(300 \mathrm{mg} / \mathrm{mL})$ was used at a dose of $0.25 \mathrm{~mL} / \mathrm{kg}$. Immediately after the slow injection of contrast (approximately $3 \mathrm{~min}$ ), radiographs were taken in the latero-lateral and ventrodorsal projections to identify the location of the spinal cord disorder. The extension degree of the lesion was evidenced by the reduction of the contrast column width at the location of instability. The patient was referred for surgical decompression and stabilization. Discussion: In cases where paraplegia results from trauma, spinal radiography and myelography are important means to confirm the diagnosis, specially the extent of the compression and prognosis. There are certain risks inherent in the myelography procedure as arrhythmias and bradycardia during collection, transient apnea during contrast injection and seizures during recovery. Furthermore, deteriorating neurological signs, emesis, urinary retention and hyperthermia are other possible complications. Most of these complications are seen predominantly during cervical myelography compared to lumbar puncture because in the first exam, the contrast hardly reaches the brain and there is no risk of iatrogenic injury to the medulla oblongata. To minimize the neurotoxic effects, the ideal contrast should be radiopaque, water soluble, miscible with the cerebrospinal fluid (CSF), nontoxic and removed from the CSF by physiological processes. Iohexol contrast was used effectively, without neurotoxicity upon clinical evaluation while the volume used was sufficient to determine the injury site. The reported case demonstrated the possibility of performing lumbar myelography on Procyon cancrivorus effectively without significant complications or difficulties.
\end{abstract}

Keywords: wildlife, neurology, myelographic examination, Procyon cancrivoru. Jaboticabal, SP, Brazil. ${ }^{2}$ Laboratório de Ortopedia e Traumatologia Comparada (LOTC), Faculdade de Medicina Veterinária e Zootecnia (FMVZ), Universidade de São Paulo (USP), São Paulo, SP, Brazil. ${ }^{3}$ Departamento de Clínicas Veterinárias, Universidade Estadual de Londrina (UEL), Londrina, PR, Brazil. ${ }^{4}$ Departamento de Patologia Veterinária, Faculdade de Ciências Agrárias e Veterinárias (FCAV), Universidade Estadual Paulista (UNESP), Jaboticabal. CORRESPONDENCE: C.C. Zani [carolzani_vet@yahoo.com.br - Tel.: +55 (43) 9602-9200]. Universidade Estadual de Londrina - UEL. Rod. Celso Garcia Cid, Pr 445 Km 380, Campus Universitário. CEP 86057-970 Londrina, PR, Brazil. 


\section{INTRODUCTION}

The Crab-eating raccoon (Procyon cancrivorus) is a nocturnal mammal that belongs to the family Procyonidae. It is geographically distributed in Central and South America, and in Brazil it can be found throughout the country, particularly in the savannah [2]. As loss of their natural habitats increase, cases of traffic accidents on the roads that result in injuries become more frequent. Often, the traumas are associated with vertebral fractures and spinal cord compression [10]. The lack of knowledge about the anatomy of these patients hinders the correct interpretation of the tests since there is little or no description about those in the literature [12].

Myelography is a radiographic technique indicated for compressive lesions of the spinal cord that are not apparent on plain radiographs, being especially indicated when there is clinical suspicion based on neurological examination. Myelography also allows you to confirm the lesion previously visualized on plain radiography, assess its extent and define the therapeutic intervention, including surgical or non-surgical cases $[6,10]$. Plain radiographs do not detect fractures and dislocations in approximately $25 \%$ of the cases [7].

There are few reports in the veterinary literature about performing myelography in wildlife $[4,5,12]$. The present report aims to describe for the first time a lumbar myelography performed in a free living adult Crab-eating raccoon (Procyon cancrivorus). This technique is essential for the diagnosis and prognosis of traumatic vertebral and spinal cord diseases in wildlife since the neurological examination is not feasible in most cases due to behavioral issues, necessitating chemical restraint.

\section{CASE}

A free living adult of the species Procyon cancrivorus (raccoon), $8 \mathrm{~kg}$, presenting acute paraplegia and swelling in the region of the left humerus after a collision with a motor vehicle on Highway Mario Donega between Pradópolis and Ribeirão Preto, Northeastern São Paulo, was referred at the veterinary hospital, in October 2011.

The 8-kg female patient was alert and aggressive, had presented good body score and no signs of active bleeding or visible injuries. At that point, paraplegia of the hind limbs and large volume increase in the left humeral region was also observed. The animal temper did not allow approaching it; therefore, physical and neurological examinations were not feasible.
The raccoon was referred for radiology, where after physical restraint using leather glove, it was administered $1.6 \mathrm{~mL}$ of Nilperidol ${ }^{\circledR}$ (fentanyl hydrochloride $0.0785 \mathrm{mg} / \mathrm{mL}+$ droperidol $2.5 \mathrm{mg} / \mathrm{mL})^{1}$ intramuscularly as tranquilizer, followed by venipuncture. After $15 \mathrm{~min}$ utes the patient had calm down however, it did not allow manipulation. Therefore, it was necessary to anesthetize with propofol ${ }^{1}$ dose-effect intravenous.

After anesthesia, tracheal intubation was induced to provide $100 \%$ oxygen and the patient was monitored continuously by electrocardiography (ECG). The respiratory parameters such as partial oxygen saturation $\left(\mathrm{SpO}_{2}\right)$, respiratory rate $(\mathrm{RR})$ and end-tidal carbon dioxide $\left(\mathrm{ETCO}_{2}\right)$ were also monitored. The electrocardiogram showed no significant change; maintaining sinus rhythm with heart rate (HR) ranging from 150 to 170 beats per minute, $\mathrm{SpO}_{2}$ (partial oxygen saturation ) remained between $97-98 \%$, RR (respiratory rate) from 10 to 12 breaths per min and $\mathrm{ETCO}_{2}$ (end-tidal carbon dioxide) from 44 to $49 \mathrm{mmHg}$.

During auscultation, no abnormal heart or lung sounds were heard while mucous membranes were opaque and normal colored. Rectal temperature was $37.5^{\circ} \mathrm{C}$, capillary refill time of 3 seconds, and increased skin turgor, suggesting mild dehydration. The simple radiograph showed a complete transverse fracture in the humerus and compression fracture of the twelfth thoracic vertebra (T12) [Figure 1], being then indicated the myelographic examination to assess the extent of spinal cord compression.

The lumbar region from the first sacral vertebra to the last was extensively shaved, followed by surgical antisepsis. After being properly positioned in lateral decubitus with moderate cranial flexion of the trunk, the patient underwent lumbar puncture by inserting a spinal needle between the 5th and 6th intervertebral lumbar spaces. The spinal needle was introduced slightly caudolaterally to the spinous process of the 6th lumbar vertebra and cranioventrally directed at an angle of $45^{\circ}$. Then, the needle was pierced through the ligamentum flavum and the dura mater while, concomitantly, we observed the tail moving and the cerebrospinal fluid (CSF) output while the contrast was injected.

The contrast iohexol ${ }^{2}(300 \mathrm{mg} / \mathrm{mL})$ was used at a dose of $0.25 \mathrm{~mL} / \mathrm{kg}$. Immediately after the slow injection of contrast (approximately $3 \mathrm{~min}$ ), radiographs were taken in the latero-lateral and ventrodorsal projec- 
tions to identify the location of the spinal cord disorder. The extension degree of the lesion was evidenced by the reduction of the contrast column width at the location of instability (Figures 2A and 2B).

The contrast neurotoxicity was not significant and the volume used was sufficient to determine injury site. The patient was referred for surgical decompression and stabilization.

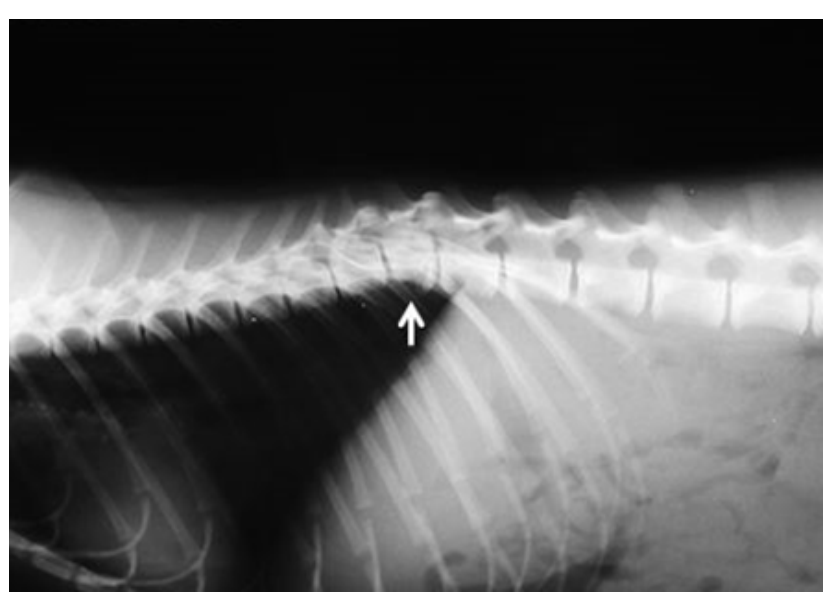

Figure 1. Radiographic image from a Procyon cancrivorus on latero-lateral projection, where the compression fracture at T12 (arrow) is observed.

\section{DISCUSSION}

Paraplegia cases in wildlife often make unfeasible to maintain their lives and euthanasia becomes necessary in most cases. The factors that must be taken into account include the severity of the injuries, animal species, character, behavior, management, requirements and long-term perspective $[2,4]$. In cases where paraplegia results from fractures and/or dislocations, spinal radiography and myelography are important means to confirm the diagnosis, specially the extent of the compression and the determination of the prognosis.

Despite the diagnostic value of myelography, there are certain risks inherent in the procedure that may occur from the collection of cerebrospinal fluid to the recovery room. The patient may present arrhythmias and bradycardia during collection, transient apnea during contrast injection and also seizures during recovery. Furthermore, deteriorating neurological signs, emesis, urinary retention and hyperthermia are other possible complications. Most of these complications are seen predominantly during cervical myelography compared to lumbar puncture because in the first exam, the contrast hardly reaches the brain and there is no risk of iatrogenic injury to the medulla oblongata $[3,9]$.

To minimize the neurotoxic effects without impairing the effectiveness of myelography, the ideal contrast, used in safe concentrations, should be radiopaque, water soluble, miscible with the cerebrospinal fluid (CSF), nontoxic and removed from the CSF by physiological processes, but not so quickly to impair the obtaining of the radiographic images [3]. In this report, the contrast iohexol was used effectively, without significant neurotoxicity upon clinical evaluation
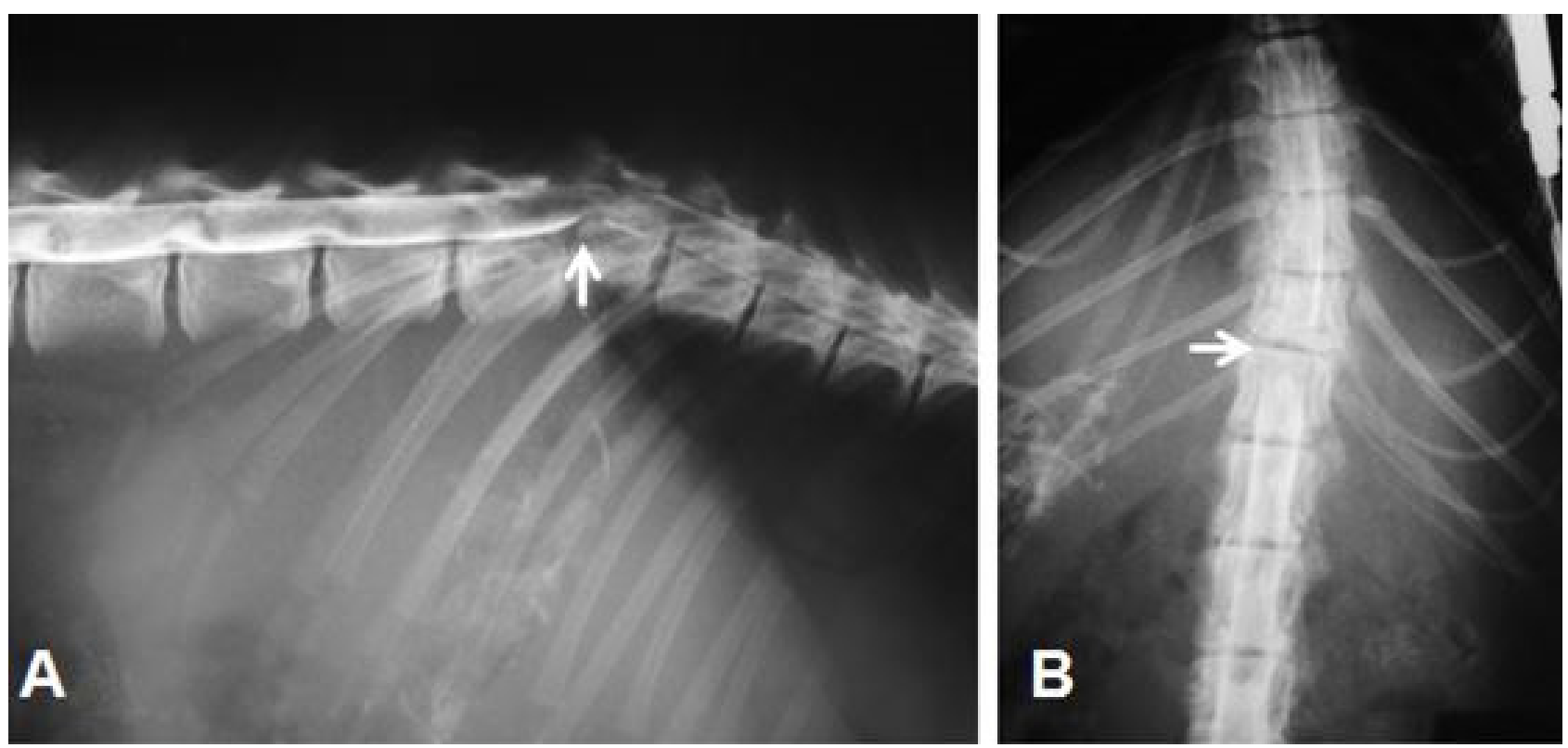

Figure 2. Lumbar myelographic image of the Crab-eating raccoon spinal cord. (A) The latero-lateral projection shows the compressive fracture of the T12 vertebral body with increased contrast column at the fracture level (arrow). (B) Ventro-dorsal projection with reduced contrast column on the right and left side at the intervertebral space between T12 and T13 (arrow). 
while the volume used was sufficient to determine the injury site.

Although the sternal recumbency position with flexed hindlimbs allows more clearance between the 5th and 6th lumbar spaces [11] and facilitates the insertion of the needle during puncture in dogs; in this case, lateral decubitus and semi-flexed hindlimbs were effective for the puncture.

Despite the possibility of contrast epidural deposition, in the lumbar puncture technique, the contrast flows under pressure to delineate the injury. The advantage of the lumbar injection lies in the antegrade flow under injection pressure and can be driven around the injury-inducing obstruction to the flow of CSF [14].

Contrast lumbar injection under ten seconds and radiographs obtained immediately after the application enhance the area of the spinal cord edema. In this case, contrast was injected slowly without interfering in the delimitation of the edema, thus avoiding inadvertent application in the epidural space [8]. The rapid application of the contrast under pressure can move the needle from the subarachnoid space and cause epidurography [13]. One of the main complications resulting from lumbar puncture while performing myelography is the inadvertent injection or extravasation of contrast into the epidural space, which results in artifacts and inconclusive images [1].

The first radiographs were performed immediately after contrast injection. Shortening the average time between injection and the first lumbar contrast radiographic exposure may influence the amount of swelling of the spinal cord visible in the myelography [13].

In spite of species anatomical and physiological differences, the reported case demonstrated the possibility of performing lumbar myelography on Procyon cancrivorus, as it has been described in dogs, mainly due to the fact that the technique was carried out effectively without significant complications or difficulties. Some authors report successfully performed myelography on Sphiggurus villosus (Hedgehog) by puncturing the cisterna magna [12]. Myelography was also reported for the species Panthera Leo (African Lion) [5] and Panthera tigris altaica (Amur Tiger) [4] demonstrating the possibility of using this technique in wild cats. Although there have been few reports in the literature, the ones available have proved the benefit of diagnostic myelography and the feasibility of the technique.

In conclusion, the lumbar myelography technique on Procyon cancrivorus was feasible, effective and essential for the accurate determination of the extent of the patient's spinal cord compression.

\section{MANUFACTURERS \\ ${ }^{1}$ Cristália. São Paulo, SP, Brazil. \\ ${ }^{2}$ Sanofi. São Paulo, SP, Brazil.}

Declaration of interest. The authors report no conflicts of interest. The authors alone are responsible for the content and writing of the paper.

\section{REFERENCES}

1 Barone G., Ziemer L.S., Shofer F.S. \& Steinberg S.A. 2002. Risk factors associated with development of seizures after use of iohexol for myelography in dogs: 182 cases (1998). Jounal fo the American Veterinary Medical Association. 220(10): 1499-1502.

2 Costa R.C., Dobson H. \& Parent J.M. 2011. Incidence of and risk factors for seizures after myelography performed with iohexol in dogs: 503 cases (2002-2004). Jounal fo the American Veterinary Medical Association. 238(10): 1296-1300.

3 Cubas Z.S., Silva J.C.R. \& Catão-Dias J.L. 2014. Carnivora-Procyonidae (Quati, Mão-pelada, Jupará). In: Tratado de Animais Selvagens: medicina veterinária. São Paulo: Roca, p.571.

4 Flegel T., Böttcher P., Alef M., Kielfer I., Ludewing E., Thielebein J \& Grevel V. 2008. Continuous lumbar hemilaminectomy for intervertebral disc disease in an Amur tiger (Panthera tigris altaica). Journal of Zoo and Wildlife Medicine. 39(3): 468-471.

5 Galloway D.S., Coke R.L., Rochat M.C., Radinsky M.A., Hoover J.P., Carpenter J.W., Hubbard J.J. \& Ketz-Riley C.J. 2002. Spinal compression due to atlantal vertebral malformation in two African lions (Panthera leo). Journal of Zoo and Wildlife Medicine. 33(3): 249-255.

6 Kealy J.K. \& Mcallister H. 2005. Radiologia e Ultrassonografia do Cão e do Gato. 3.ed. Barueri: Manole, pp.339-384. 7 Kinns J., Mai W., Seiler G., Zwingenberger A., Johnson V., Cáceres A., Valdés-Martínez A. \& Schwarz T. 2006. Radiographic sensitivity and negative predictive value for acute canine spinal trauma. Veterinary Radiology \& Ultra- 
B.W. Minto, P.E.S. Silva, P.V.T. Marinho, et al. 2016. Lumbar Myelography in a Crab-Eating Raccoon (Procyon cancrivorus). Acta Scientiae Veterinariae. 44(Suppl 1): 115.

sound. 47(6): 563-570.

8 Kirberger R.M., Roos C.J. \& Lubbe A.M. 1992. The radiological diagnosis of thoracolumbar disc disease in the dachshund. Veterinary Radiology \& Ultrasound. 33(5): 255-261.

9 Kishimoto M., Yamada K., Ueno H., Kobayashi Y. \& Wisner E.R. 2004. Spinal cord effects from lumbar myelographic injection technique in the dog. Journal of Veterinary Medical Science. 66(1): 67-69.

10 Mcevoy F.J. 2006. Spine - conditions not related to intervertebral disc disease. In: Barr F.J. \& Kirberger R.M. (Eds). Manual of canine and feline musculoskeletal imaging. Gloucester: BSAVA, p.234.

11 Puggioni A., Arnett R., Clegg T., Glyde M., Tobin E. \& McAllister H. 2006. Influence of patient positioning on the L5-L6 mid-laminar distance. Veterinary Radiology \& Ultrasound. 47(5): 449-452.

12 Sant'Anna N.T., Silva B.S., Soresini G.C. \& Silva L.C.S. 2012. Mielografia em ouriço-cacheiro (Sphiggurus villosus). Arquivo Brasileiro de Medicina Veterinária e Zootecnia. 63(1): 64-66.

13 Taeymands O., Saunders J.H. \& Breed H.N. 2002. Radiology Corner Canine myelography. Veterinary Radiology \& Ultrasound. 43(6): 550-551.

14 Toombs J.P. \& Waters D.J. 2007. Afecção do disco intervertebral. In: Slatter D. (Ed). Manual de cirurgia de pequenos animais. São Paulo: Manole, pp.1193-1208. 